\title{
Fisioterapi Dada Dan Batuk Efektif Sebagai Penatalaksanaan Ketidakefektifan Bersihan Jalan Nafas Pada Pasien TB Paru Di RSUD Kota Kendari
}

\author{
Rusna Tahir ${ }^{1}$, Dhea Sry Ayu Imalia $\mathbf{S}^{2}$, Siti Muhsinah ${ }^{3}$ \\ ${ }^{123}$ Jurusan Keperawatan Poltekkes Kemenkes Kendari
}

\begin{abstract}
Backgorund: Pulmonary tuberculosis is an infection disease with the highest prevalence in the world and being the third largest in Indonesia with 1.02 million cases. The core problem of pulmonary tuberculosis patient is ineffective airway clearance characterized by dyspnea, ronchi, excessive sputum, ineffective cough. Nursing intervention to manage the problem is chest physiotherapy and effective coughing. Objective: This study aims to obtain an overview of the application of chest physiotherapy and effective coughing as ineffective airway clearance management on pulmonary tuberculosis patient. Method: Method used descriptive case study with structured interview, studies document and observations. Participants in this study is pulmonary tuberculosis patient which is given three days and twice a day session of chest physiotherapy and effective coughing. Results: Patency of the airway is improve after chest physiotherapy and effective coughing which characterized by normal respiratory frequencies, normal respiratory rythms, no ronchi and able to remove sputum from airway. Conclusion: Chest physiotherapy and effective coughing is applicable as ineffective airway clearance management on pulmonary tuberculosis patient.
\end{abstract}

Keywords : pulmonary tuberculosis, ineffective clearance airway, chest physiotherapy and effective coughing

PENDAHULUAN

Latar Belakang

Tuberkulosis (TB) merupakan penyakit menular yang menyebabkan kematian tertinggi kedua di dunia setelah HIV/AIDS (WHO, 2015). World Health Organization (WHO) menunjukkan peningkatan prevalensi kasus TB dari 9,6 juta menjadi 10,4 juta pada tahun 2016. Indonesia menduduki peringkat kedua dunia dengan penyakit TB terbanyak yaitu 1,2 juta kasus dengan angka kematian 100.000 jiwa setiap tahun (Global Tuberculosis Report, 2016).

Kejadian TB di Sulawesi Tenggara bukan yang tertinggi di Indonesia, akan tetapi mengalami peningkatan jumlah setiap tahun. Pada Tahun 2017 tercatat sebanyak 2.587 kasus baru BTA positif, yang tersebar pada empat Kabupaten dengan penderita terbanyak yakni Kota Kendari, Kabupaten Konawe, Kolaka, dan Bau-Bau. Di RSUD Kota Kendari sebagai salah satu RS rujukan Provinsi, tercatat 545 penderita TB dalam rekam medis pernah menjalani perawatan di 2017 (Rekam Medik RSUD Kota Kendari, 2018). Angka ini diperkirakan terus mengalami lonjakan seiring dengan bertambahnya populasi masyarakat yang tinggal di Kota Kendari. \begin{tabular}{lccc}
\multicolumn{2}{c}{ Penyakit $\mathrm{TB}$ paru ditularkan melalui } \\
airborne yaitu inhalasi droplet yang \\
mengandung & kuman & mycobacterium
\end{tabular} tuberculosis. Pasien TB paru akan mengeluh batuk yang disertai dahak dan atau batuk berdarah, sesak napas, nyeri pada daerah dada, keringat pada malam hari, penurunan nafsu makan. Pemeriksaan fisik menunjukkan tandatanda berupa peningkatan frekuensi napas, irama nafas tidak teratur, dan ronchi (Ardiansyah, 2012). Merujuk pada manifestasi tersebut, masalah keperawatan yang umum terjadi pada pasien TB paru adalah ketidakefektifan bersihan jalan napas (Herdman, 2018).

Ketidakefektifan bersihan jalan nafas adalah ketidakmampuan membersihkan sekresi atau penyumbatan pada saluran nafas untuk mempertahankan bersihan jalan nafas (Herdman, 2018). Obstruksi saluran napas disebabkan oleh menumpuknya sputum pada jalan napas yang akan mengakibatkan ventilasi menjadi tidak adekuat. Untuk itu perlu dilakukan tindakan memobilisasi pengeluaran sputum agar proses pernapasan dapat berjalan dengan baik guna mencukupi kebutuhan oksigen tubuh (Endrawati, Aminingsih S, \& Ariasti D, 2014).

Salah satu intervensi keperawatan yang bisa diterapkan untuk membersihkan sputum pada jalan napas adalah fisioterapi dada dan batuk efektif. Banyak penelitian yang telah 
membuktikan fisioterapi dada dan dan batuk efektif dapat membantu pasien mengeluarkan sputum (Nugroho, 2011 ; Kapuk, 2012 ; Endrawati, Aminingsih S, \& Ariasti D, 2014 ; Maidartati, 2014). Fisioterapi dada dan batuk efektif dinilai efektif karena bisa dilakukan oleh keluarga, mudah dan bisa dilakukan kapan saja.

\section{Rumusan Masalah}

Berdasarkan uraian latar belakang diatas, maka rumusan masalah pada studi kasus ini adalah bagaimana penerapan fisioterapi dada dan batuk efektif sebagai penatalaksanaan ketidakefektifan bersihan jalan nafas pada pasien TB paru?

\section{Tujuan}

Tujuan pelaksanaan studi kasus ini adalah untuk mengetahui gambaran penerapan fisioterapi dada dan batuk efektif sebagai penatalaksanaan ketidakefektifan bersihan jalan nafas pada pasien TB paru di RSUD Kota Kendari.

\section{METODE}

\section{Jenis Penelitian}

Jenis penelitian ini adalah deskiftif dengan pendekatan observasional melalui studi kasus untuk memperoleh gambaran penerapan fisioterapi dada dan batuk efektif pada pasien TB paru.

\section{Lokasi dan Waktu Penelitian}

Studi kasus berlokasi di Ruang Lavender RSUD Kota Kendari. Studi kasus dilaksanakan mulai bulan Maret - April 2019.

\section{Populasi dan Sampel}

Sampel dalam studi kasus ini berfokus pada satu orang pasien yang menjalani perawatan di RSUD Kota Kendari dengan diagnosa medis TB paru dan diagnosa keperawatan ketidakefektifan bersihan jalan napas dengan kriteria yaitu pasien dengan diagnosa medis $\mathrm{TB}$ paru tanpa disertai hemaptoe, kesadaran komposmentis, tidak mengalami gangguan pada thorax dan punggung atau tulang belakang.

\section{Pengumpulan Data}

Data dalam studi kasus ini dibagi menjadi dua, yaitu data primer dan data sekunder. Data primer diperoleh dari pengkajian, observasi dan wawancara dengan pasien. Data sekunder diperoleh dari rekam medis dan wawancara dengan keluarga yang mendampingi pasien selama menjalani perawatan.

Pengkajian menggunakan format pengkajian kebutuhan oksigenasi. Alat ukur yang digunakan sebagai evaluasi tindakan adalah lembar observasi yang berisi SOP serta lembar observasi penilaian merujuk pada Nursing Outcome Clasification (NOC) serta buku Standar Luaran Keperawatan Indonesia (SLKI) untuk menilai kepatenan jalan napas yang ditandai dengan frekuensi napas (16-20x/menit), irama napas reguler, kemampuan mengeluarkan sputum, tidak ada suara napas tambahan.

Kepatenan jalan napas dievaluasi dua kali dalam sehari (pagi dan sore) selama tiga hari berturut-turut setelah tindakan fisioterapi dada dan batuk efektif (Tarwoto dan Wartonah, 2015 ; Kasanah, 2015 ; Laukhil, 2016). Fisioterapi dada dan batuk efektif dilakukan sebelum pasien minum obat untuk mengurangi bias dalam studi kasus.

\section{Pengolahan, Analisis Data, Penyajian Data}

Data diperoleh dari hasil pengkajian, observasi, wawancara dan serta studi dokumen berupa rekam medik. Data ditampilkan secara tekstural atau narasi disertai dengan ungkapan verbal dan respon dari subjek studi kasus yang merupakan data pendukung penelitian. Data menerangkan beragam aspek dari pasien kemudian dibandingkan dengan data normal sesuai rujukan referensi. Hasil analisa data-data ditampilkan dalam bentuk tabel.

\section{HASIL}

Hasil pengkajian didapatkan identitas pasien berinisial Tn. D umur 36 tahun, suku Tolaki, beragama Islam, pekerjaan Wirasuasta, pendidikan terakhir SMA, alamat Desa Lalonggombu Kecamatan Lainea Kabupaten Kobawe Selatan. Keluhan utama saat masuk RS adalah demam, batuk berlendir disertai bercak darah, sesak nafas, nafsu makan menurun, ronchi, wajah nampak pucat, mukosa bibir kering, TD 100/70 mmhg, Nadi 82x/menit, pernapasan tidak teratur dengan frekuensi (RR) 27x/menit.

Penerapan fisioterapi dada dan batuk efektif dilaksanakan selama 3 hari, dengan frekuensi latihan $2 \mathrm{x}$ dalam sehari pada pagi $(\mathrm{P})$ 
dan sore (S) hari. Hasil yang diperoleh sebagai

berikut :

a. Frekuensi pernapasan

Tabel 1. Frekuensi Pernafasaan Sebelum Dan Setelah Fisioterapi Dada Dan Batuk Efektif

\begin{tabular}{|c|c|c|c|c|c|}
\hline \multirow[b]{2}{*}{ No } & \multirow[b]{2}{*}{ Hari Latihan } & \multicolumn{4}{|c|}{ Frekuensi Nafas (Kali/Menit) } \\
\hline & & Sebelum (P) & $\begin{array}{c}\text { Setelah } \\
(\mathbf{P})\end{array}$ & $\begin{array}{l}\text { Sebelum } \\
(\mathrm{S})\end{array}$ & $\begin{array}{c}\text { Setelah } \\
\text { (S) }\end{array}$ \\
\hline 1 & Hari 1 & $27 x / m e n i t$ & $27 \mathrm{x} / \mathrm{menit}$ & $27 \mathrm{x} / \mathrm{menit}$ & $27 \mathrm{x} / \mathrm{menit}$ \\
\hline 2 & Hari 2 & $27 x /$ menit & 26x/menit & $26 \mathrm{x} / \mathrm{menit}$ & $25 \mathrm{x} / \mathrm{menit}$ \\
\hline 3 & Hari 3 & $25 \mathrm{x} / \mathrm{menit}$ & $24 \mathrm{x} / \mathrm{menit}$ & $24 \mathrm{x} / \mathrm{menit}$ & $24 \mathrm{x} / \mathrm{menit}$ \\
\hline
\end{tabular}

Dari tabel diatas dapat dilihat bahwa setelah dilakukan tindakan fisioterapi dada dan batuk efektif terjadi penurunan RR dari 27x/menit menjadi 26x/menit pada hari kedua

b. Suara napas tambahan sesi pagi dan dari 26x/menit menjadi $25 x /$ menit pada sesi sore. Terjadi penurunan dari 25x/menit menjadi 24x/menit (RR normal) pada hari ketiga pada sesi pagi dan sore hari.

Tabel 2. Suara Napas Tambahan Sebelum Dan Setelah Fisioterapi Dada Dan Batuk Efektif

\begin{tabular}{llcccc}
\hline \multirow{2}{*}{ No } & Hari Latihan & $\begin{array}{c}\text { Sebelum } \\
(\mathbf{P})\end{array}$ & $\begin{array}{c}\text { Setelah } \\
(\mathbf{P})\end{array}$ & Sebelum $(\mathbf{S})$ & $\begin{array}{c}\text { Setelah } \\
(\mathbf{S})\end{array}$ \\
\cline { 3 - 6 } & & Ada(ronchi) & Ada(ronchi) & Ada(ronchi) & Ada(ronchi) \\
\hline 1 & Hari 1 & Ada(ronchi) & Ada(ronchi) & Ada(tonchi) & Tidak ada \\
\hline 2 & Hari 2 & Tidak ada & Tidak ada & Tidak ada & Tidak ada \\
\hline
\end{tabular}

Dari tabel diatas dapat dilihat bahwa setelah dilakukan tindakan fisioterapi dada dan batuk efektif suara napas tambahan (ronchi) tidak terdengar lagi pada hari kedua sesi sore sampai pada hari ketiga baik pada sesi pagi maupun sore.

c. Irama napas

Tabel 3. Irama Pernapasan Sebelum Dan Setelah Fisioterapi Dada Dan Batuk Efektif

\begin{tabular}{llcccc}
\hline \multirow{2}{*}{ No } & Hari Latihan & $\begin{array}{c}\text { Sebelum } \\
(\mathbf{P})\end{array}$ & $\begin{array}{c}\text { Setelah } \\
(\mathbf{P})\end{array}$ & $\begin{array}{c}\text { Sebelum } \\
(\mathbf{S})\end{array}$ & $\begin{array}{c}\text { Setelah } \\
(\mathbf{S})\end{array}$ \\
\hline 1 & Hari 1 & Tidak teratur & Tidak Teratur & Tidak teratur & Tidak Teratur \\
\hline 2 & Hari 2 & Tidak teratur & Tidak steratur & Tidak teratur & Teratur \\
\hline 3 & Hari 3 & Teratur & Teratur & Teratur & Teratur \\
\hline
\end{tabular}

Dari tabel diatas dapat dilihat bahwa setelah dilakukan tindakan fisioterapi dada dan batuk efektif terjadi perubahan irama napas dari tidak teratur menjadi teratur pada hari kedua sesi sore. Selanjutnya pada hari ketiga irama napas normal baik pada sesi pagi maupun sore. 
d. Kemampuan mengeluarkan sputum

Tabel 3. Kemampuan Mengeluarkan Sputum Sebelum Dan Setelah Fisioterapi Dada Dan Batuk Efektif

\begin{tabular}{cccccc}
\hline \multirow{2}{*}{ No } & Hari Latihan & \multicolumn{4}{c}{ Kemampuan mengeluarkan sputum } \\
\cline { 3 - 6 } & $\begin{array}{c}\text { Sebelum } \\
(\mathbf{P})\end{array}$ & $\begin{array}{c}\text { Setelah } \\
(\mathbf{P})\end{array}$ & $\begin{array}{c}\text { Sebelum } \\
(\mathbf{S})\end{array}$ & $\begin{array}{c}\text { Setelah } \\
(\mathbf{S})\end{array}$ \\
\hline 1 & Hari 1 & Tidak & Mampu & Mampu & Mampu \\
& & Mampu & & & \\
\hline 2 & Hari 2 & Mampu & Mampu & Mampu & Mampu \\
\hline 3 & Hari 3 & Mampu & Mampu & Mampu & Mampu \\
\hline
\end{tabular}

Dari tabel diatas dapat dilihat bahwa setelah dilakukan tindakan fisioterapi dada dan batuk efektif pasien mampu (M) mengeluarkan sputum pada hari pertama sesi pagi sampai hari ketiga.

e. Kepatenan jalan napas

Tabel 4. Kepatenan Jalan Napas Sebelum Dan Setelah Fisioterapi Dada Dan Batuk Efektif

\begin{tabular}{|c|c|c|c|c|c|c|c|c|c|c|}
\hline \multirow{3}{*}{ Hari } & \multicolumn{10}{|c|}{ KEPATENAN JALAN NAFAS } \\
\hline & \multicolumn{2}{|c|}{$\begin{array}{c}\text { RR } \\
\text { (kali/menit) }\end{array}$} & \multicolumn{2}{|c|}{$\begin{array}{c}\text { Irama } \\
\text { Pernafasan }\end{array}$} & \multicolumn{2}{|c|}{$\begin{array}{c}\text { Suara Nafas } \\
\text { Tambahan }\end{array}$} & \multicolumn{2}{|c|}{$\begin{array}{c}\text { Kemampuan } \\
\text { Mengeluaran } \\
\text { Sekret }\end{array}$} & \multicolumn{2}{|c|}{ Kriteria } \\
\hline & S.1 & S.2 & S.1 & S.2 & $\mathrm{S} 1$ & S2 & S.1 & S.2 & S.1 & S.2 \\
\hline 1 & 27 & 27 & TT & TT & Ada & Ada & $\mathrm{M}$ & $\mathrm{M}$ & $\mathrm{TP}$ & $\mathrm{TP}$ \\
\hline 2 & 26 & 25 & TT & $\mathrm{T}$ & Ada & Tidak ada & $\mathrm{M}$ & $\bar{M}$ & $\mathrm{TP}$ & $\mathrm{P}$ \\
\hline 3 & 24 & 24 & $\mathrm{~T}$ & $\mathrm{~T}$ & Tidak ada & Tidak ada & $\mathrm{M}$ & $\mathrm{M}$ & $\mathrm{P}$ & $\mathrm{P}$ \\
\hline
\end{tabular}

Dari tabel diatas dapat dilihat bahwa setelah dilakukan tindakan fisioterapi dada dan batuk efektif terjadi perubahan kepatenan jalan napas pada hari kedua sesi sore hari yang ditandai dengan RR normal (24x/menit), irama napas teratur, tidak ada ronchi, serta pasien mampu mengeluarkan sputum. Kepatenan jalan napad dapat dipertahankan sampai hari ketiga.

\section{PEMBAHASAN}

Subjek studi kasus dalam hal ini adalah pasien TB paru mengalami masalah keperawatan ketidakefektifan bersihan jalan napas. Berdasarkan Nursing Intervention Clasification (NIC), salah satu intervensi mandiri yang dapat dilakukan perawat untuk mengatasi masalah tersebut adalah fisioterapi dada dan mengajarkan teknik batuk efektif (Bulechek, \& Butcher, 2013). Sedangkan keberhasilan intervensi ini dinilai berdasarkan kepatenan jalan napas yang terdiri dari empat kriteria hasil yaitu frekuensi napas, irama napas, suara napas tambahan, dan kemampuan mengeluarkan sputum (Moorhead, S \& Johnson, M, 2013). Pembahasan masingmasing kriteria hasil sebagai berikut :

\section{a. Frekuensi Pernapasan}

Pada hari pertama pelaksanaan tindakan fisioterasi dada dan batuk efektif, hasil yang diperoleh yaitu terjadi penurunan RR pada hari kedua yaitu 26x/menit dan hari ketiga menjadi normal (24x/menit). Hasil ini sejalan dengan penelitian Sitorus, Lubis dan Kristiani (2018) pada pasien TB paru dengan hasil yaitu suara 
nafas normal/vesikuler, RR 24x/menit, TD 100/70mmHg, N 89x/menit, S $37^{\circ} \mathrm{C}$. Juga didukung oleh penelitian Tarwoto dan Wartonah (2015) melalui evaluasi pasien selama 3 hari setelah tindakan fisioterapi dada yaitu penurunan RR dari 27x/menit menjadi 22x/menit. Penelitian sebelumnya membuktikan bahwa adanya kesesuaian terhadap hasil yang dicapai yaitu frekuensi napas menjadi normal.

Mobilisasi sputum dari saluran napas setelah fisioterapi dada akan membuat rongga alveoli menjadi lebih lebar sehingga tekanannya mengecil mengakibatkan pengembangan alveoli lebih maksimal. Pengembangan alveoli secara maksimal akan mendukung ventilasi yang adekuat untuk dapat meningkatkan asupan oksigen yang lebih banyak keparu sehingga mengurangi keluhan sesak napas pada pasien (Khotimah, 2013).

\section{b. Suara Napas Tambahan}

Hasil penelitian menunjukkan bahwa setelah dilakukan latihan fisioterapi dada dan batuk efektif suara napas tambahan (ronchi) tidak terdengar lagi pada hari kedua sesi sore sampai pada hari ketiga baik pada sesi pagi maupun sore. Bunyi ronchi disebabkan karena aliran udara melalui saluran nafas yang berisi sputum atau eksudat. Sputum dijalan nafas dapat dimobilisasi keluar melalui fisioterapi dada dan batuk efektif (Kusuma, 2015).

Keluarnya sputum membuat saluran nafas bebas dari sputum sehingga tidak terdengar lagi ronchi. Hal ini ditunjang dengan teori yang menyebutkan bahwa batuk efektif akan membantu proses pengeluaran sekret yang menumpuk pada jalan nafas sehingga tidak ada lagi perlengketan pada jalan nafas sehingga jalan nafas paten dan sesak nafas berkurang (Nugroho, 2011).

\section{c. Irama Pernapasan}

Hasil penelitian menunjukkan bahwa setelah tindakan fisioterapi dada dan batuk efektif terjadi perubahan irama napas dari tidak teratur menjadi teratur pada hari kedua sesi sore. Selanjutnya pada hari ketiga irama napas normal baik pada sesi pagi maupun sore. Perubahan irama napas terjadi seiring dengan normalnya frekuensi pernapasan.

Frekuensi nafas yang normal dan keteraturan irama pernafasan terjadi kerena kecukupan suplai oksigen dalam paru yang akan didistibusikan ke suluruh tubuh. Saluran napas yang bebas dari sekret yang menumpuk akan memudahkan transport oksigen dari saluran pernapasan menuju paru-paru. Kecukupan suplay oksigen dalam tubuh ditandai dengan AGD dalam batas normal (McPhee \& Ganong, 2010).

\section{d. Kemampuan Mengeluarkan Sputum}

Kemampuan mengeluarkan sekret pasien ditunjukkan pada hari pertama sampai hari terakhir pemberian tindakan fisioterapi dada dan batuk efektif. Kemampuan mengeluarkan sekret berkaitan dengan kemampuan pasien melakukan batuk efektif. Batuk yang efektif dapat mendorong sekret yang menumpuk pada jalan nafas untuk keluar. Setelah dilakukan latihan fisioterapi dada dan batuk efektif selama 3 hari maka didapatkan hasil bahwa pasien mampu mengeluarkan sekret karena bisa melakukan batuk dengan efektif.

Hal ini ditunjang dengan teori yang menyebutkan bahwa dengan dilakukan batuk efektif akan membantu proses pengeluaran sekret yang menumpuk pada jalan nafas sehingga tidak ada lagi perlengketan pada jalan nafas sehingga jalan nafas paten dan sesak nafas berkurang (Nugroho, 2011).

\section{e. Kepatenan Jalan Napas}

Hasil penelitian menunjukkan bahwa setelah dilakukan tindakan fisioterapi dada dan batuk efektif terjadi perubahan kepatenan jalan napas pada hari kedua sesi sore hari yang ditandai dengan $R R$ normal (24x/menit), irama napas teratur, tidak ada ronchi, serta pasien mampu mengeluarkan sputum. Kepatenan jalan napad dapat dipertahankan sampai hari ketiga.

Indikator dari kepatenan jalan napas adalah RR normal, irama napas teratur, tidak ada suara napas tambahan, serta pasien mampu mengeluarkan sputum dari jalan napas. Kepatenan jalan napas dapat dicapai melaui tindakan fisoterapi dada dan batuk efektif karena tindakan ini dapat memobilisasi secret di saluran napas yang meningkatkan fungsi respirasi (Maidartati, 2014 ; Laukhil, 2016). Jalan napas yang paten merupakan target luaran atau kriteria hasil dari diagnosa ketidakefektifan bersihan jalan napas (Herdman, 2018).

Berdasarkan hasil penelitian yang dilakukan oleh peneliti dengan ditunjang oleh teori dan hasil-hasil penelitian sebelumnya maka peneliti berasumsi bahwa fisioterapi dada dan batuk efektif dapat digunakan sebagai 
penatalaksanaan ketidakefektifan bersihan jalan nafas pada pasien TB paru (Apriyadi, 2013 ; Mardiono, 2013 ;)

\section{KESIMPULAN DAN SARAN}

Kesimpulan dari studi kasus ini adalah fisioterapi dada dan batuk efektif dapat digunakan sebagai penatalaksanaan ketidakefektifan bersihan jalan nafas pada pasien TB paru dengan kriteria hasil kepatenan jalan napas yang ditandai dengan frekuensi napas normal, irama napas teratur, tidak ada suara napas tambahan, pasien mampu mengeluarkan sputum.

Peneliti berharap bahwa tenaga perawat lebih banyak lagi menerapkan intervensi mandiri seperti fisioterapi dada dan batuk efektif karena sudah terbukti secara empiris (evidence based) bisa mengatasi masalah ketidakefektifan bersihan jalan napas khususnya pada pasien TB paru.

\section{DAFTAR PUSTAKA}

Apriadi. (2013). Latihan nafas dalam dan batuk efektif. Jakarta: EGC

Ardiansyah, M. (2012). Buku Ajar Medical Bedah. Jakarta : Diva Pres

Bulechek, GM \& Butcher, HK. (2013). Nursing Intervention Classification. Jakarta: Elseiver Global Rights

Endrawati, Aminingsih S, dan Ariasti D. 2014. Pengaruh Pemberian Fisioterapi Dada Terhadap Kebersihan Jalan Napas pada Pasien ISPA di Desa Pucung Eromoko Wonogiri. Kosala. Volume 2 Nomor 2 September 2014. Hal: 28

Herdman, T. Heather. (2018). NANDA-I Diagnosis Keperawatan : defenisi dan klasifikasi 2018-2020. Jakarta : EGC

Kasanah. (2015) . Efektifitas batuk efektif dan fisioterapi dada terhadap pengeluaran sputum. Diakses tanggal 10 Mei 2019 http://ejournal.stikestelogorejo.ac.id/inde x.php/ilmukeperawatan/article/viewFile/4 $47 / 447$

Khotimah, S. (2013). Latihan edurance Meningkatkan Kualitas Hidup Lebih Baik Dari Pad Latihan Pernafasan Pada Pasien PPOK di BP4 Yogyakarta. Sport and Fitnes Journal. Juni 2013 : 1. No. 20-23

Kusuma, H. (2015). Hand Book For Health Student. Yogyakarta : Mediaction Publishing
Laukhil, M. (2016). Penerapan Batuk Efektif Pada Pasien Bronkopneumonia Dengan Masalah Keperawatan Ketidakefektifan Bersihan Jalan Nafasa Di Ruang Melatih Rumah Sakit Islam Jemursari Surabaya. Surabaya : University of Nahdlatul Ulama Surabaya repository : . http://repository.unusa.ac.id/id/eprint/126 $\underline{6}$

Maidartati. (2014). Pengaruh fisioterai dada terhadap bersihan jalan napas pada anak usia 1-5 tahun yang mengalami gangguan bersihan jalan napas di Puskesmas Moch Ramdhan Bandung. Jurnal Ilmu Keperawatan. Volume 11

Mardiono, S. (2013). Pengaruh Latihan Batuk Eektif Terhadap Frekuensi Pernafasan Pasien TB Paru di Instalasi Rawat Inap Penyakit Dalam Rumah Sakit Pelabuhan Palembang Tahun 2013. Jurnal Harapan Bangsa , 224- 229

McPhee, Stephen J dan Ganong, William F.(2010). Patofisiologi penyakit: pengantar menujuh kedokteran klinis/Stephen J. McPhee, William F. Ganong; ahli bahasa, Brahm U. Pendit.; editor bahasa Indonesia. Frans Dany, Edisi 5. Jakarta: EGC

Moorhead, S \& Johnson, M. (2013). Nursing outcome classification. Jakarta : Elseiver Global Rights

Nugroho Y A \& Kristiani E E. (2011). Batuk Efektif Dalam Pengeluaran Dahak Pada Pasien Dengan Ketidakefektifan Bersihan Jalan Napas di Instalasi 20 Rehabilitasi Medik Rumah Sakit Baptis Kediri. Jurnal STIKES RS Baptis Kediri Volume 4 Nomor 2.

Tarwoto dan Wartonah. (2015). Kebutuhan Dasar Manusia dan Proses Keperawatan Edisi :4 .Jakarta

Sitorus, Lubis, Kristiani. (2018). Penerapan batuk efektif dan fisioterapi dada pada pasien TB Paru yang mengalami ketidakefektifan bersihan jalan napas di RSUD Koja Jakarta Utara. JAKHKJ Vol. 4, No. 2

World Heart Organization. (2016). Global Tuberculosis Report 2016. Diakses tanggal $\quad 10 \quad$ Mei 2019 https://apps.who.int/iris/bitstream/handle/ 10665/250441/9789241565394eng.pdf;jsessionid=E23B023FD23385C17 832D671AFB2D847? sequence $=1$ 
Health Information : Jurnal Penelitian

Volume 11 no 1 Juni 2019

p-ISSN: 2085-0840: E-ISSN: 2622-5905 